\title{
Correlates of the support for smoke-free policies among smokers: A cross-sectional study in six European countries of the EUREST-PLUS ITC EUROPE SURVEYS
}

\author{
Marcela Fu ${ }^{1,2,3}$, Yolanda Castellano ${ }^{1,2}$, Olena Tigova ${ }^{1,2}$, Ute Mons ${ }^{4}$, Thomas Agar, Christina N. Kyriakos ${ }^{6,7}$, Anne C. K. \\ Quah ${ }^{5}$, Geoffrey T. Fong ${ }^{5,8}$, Antigona C. Trofor ${ }^{9,10}$, Krzysztof Przewoźniak ${ }^{11,12}$, Witold A. Zatoński"11,13, Tibor Demjén ${ }^{14}$, \\ Yannis Tountas ${ }^{15}$, Constantine I. Vardavas ${ }^{6,7 *}$, Esteve Fernández ${ }^{1,2,3 *}$, on behalf of the EUREST-PLUS Consortium ${ }^{* *}$
}

\begin{abstract}
INTRODUCTION This report describes the support for smoke-free policies in different settings among smokers in six European countries and the relationship between their opinions about the places where smoking should be banned and their beliefs about the harms of secondhand smoke to non-smokers.
\end{abstract}

METHods A cross-sectional survey (the ITC 6 European Country Survey, part of the EUREST-PLUS Project) was conducted using nationally representative samples of adult smokers in Germany, Greece, Hungary, Poland, Romania and Spain ( $n=6011)$. We describe the prevalence of agreement and support for smoke-free policies in different settings according to sociodemographics, smoking characteristics and beliefs about the danger of secondhand smoke to non-smokers.

RESULTS There was high agreement with smoking regulations in cars with preschool children and in schoolyards of primary/secondary schools ( $>90 \%$ overall) and low agreement with banning smoking in outdoor terraces of bars/pubs (8.6\%; 95\%CI: 7.5\%-9.8\%) and restaurants (10.1\%; 95\%CI: 8.9\%-11.4\%). The highest support for complete smoking bans inside public places came from smokers in Poland, among women, people aged $\geq 25$ years, who had low nicotine dependence, and who tried to quit smoking in the last 12 months. About $78 \%$ of participants agreed that tobacco smoke is dangerous to non-smokers, ranging from $63.1 \%$ in Hungary to $88.3 \%$ in Romania; the highest agreement was noted among women, the 25-54 age groups, those with higher education, low cigarette dependence, and those who tried to quit in the last 12 months. The support for complete smoking bans in public places was consistently higher among smokers who agreed that secondhand smoke is dangerous to non-smokers.

conclusions Smokers in six European countries declared strong support for smoke-free policies in indoor settings and in settings with minors but low support in outdoor settings, particularly leisure facilities. More education is needed to increase the awareness about the potential exposure to secondhand smoke in specific outdoor areas.

\section{AFFILIATION}

1 Catalan Institute of Oncology (ICO), Barcelona, Spain

2 Bellvitge Biomedical Research Institute (IDIBELL), Barcelona, Spain

3 University of Barcelona (UB), Barcelona, Spain

4 Cancer Prevention Unit and WHO

Collaborating Centre for Tobacco Control,

German Cancer Research Center (DKFZ),

Heidelberg, Germany

5 Department of Psychology and School of Public Health and Health Systems, University of Waterloo (UW), Waterloo, Canada

6 European Network for Smoking and Tobacco Prevention (ENSP), Brussels, Belgium

7 University of Crete (UoC), Heraklion, Greece

8 Ontario Institute for Cancer Research (OICR),

Toronto, Canada

9 University of Medicine and Pharmacy 'Grigore

T. Popa' Iasi (UMF lasi), Iasi, Romania

10 Aer Pur Romania (APR), Bucharest, Romania

11 Health Promotion Foundation (HPF), Warsaw, Poland

12 Maria Skłodowska-Curie Institute Oncology Center (MSCl), Warsaw, Poland

13 European Observatory of Health Inequalities, President Stanisław Wojciechowski State University of Applied Sciences (PSWZ), Kalisz, Poland

14 Smoking or Health Hungarian Foundation (SHHF), Budapest, Hungary

15 National and Kapodistrian University of Athens (UoA), Athens, Greece

${ }^{*}$ Contributed equally

\section{CORRESPONDENCE TO}

Marcela Fu. Tobacco Control Unit, Catalan Institute of Oncology, Av. Granvia de L'Hospitalet, 199-203, 08908 L'Hospitalet de Llobregat, Barcelona, Spain. E-mail: mfu@iconcologia.net

KEYWORDS

Secondhand exposure, smoke-free policies, smokers, Europe, WHO FCTC

Received: 1 December 2018

Revised: 6 February 2019

Accepted: 12 February 2019 


\section{INTRODUCTION}

Secondhand smoke is a known risk factor for preventable disease and death worldwide ${ }^{1}$. In 2009, the World Health Organization (WHO) Framework Convention on Tobacco Control (FCTC) promoted the implementation of smoke-free environments ${ }^{2}$ and since then comprehensive legislation in many countries has led to a decrease in smoking in public places, with subsequent reduction in exposure to secondhand smoke ${ }^{3}$.

Knowing the opinions and attitudes of smokers about smoking regulations in different settings is crucial to achieving smoke-free environments. The International Tobacco Control Policy Evaluation Project (the ITC Project; www.itcproject.org/) aims at tracking and comparing the impact of nationallevel tobacco policies among representative samples of adult smokers in 29 countries. Results have shown increasing support for smoke-free laws among smokers in France ${ }^{4,5}$ and Ireland ${ }^{6}$, and varied support in the $\mathrm{UK}^{7,8}$, Germany and the Netherlands ${ }^{9}$.

The ITC Project is a dynamic cohort study worldwide and many countries are continuously joining. In 2014, five new countries plus Germany started up the EUREST-PLUS Project (https:// eurestplus.eu), aiming to assess and monitor the impact of the ratification of the WHO FCTC at the European level through the implementation of the European Union (EU) Tobacco Products Directive $^{10,11}$. Following the ITC methodology, a prospective cohort study was established (the ITC 6 European Country Survey or ITC 6E Survey) in Germany, Greece, Hungary, Poland, Romania, and Spain. The implementation of smoke-free legislation in these countries has been heterogeneous ${ }^{12}$. For example, Spain has the more restrictive smoke-free legislation, banning smoking totally in indoor areas of workplaces, enclosed public places, restaurants, bars, healthcare and education facilities, as well as in public transport. Legislation in Hungary allows separate enclosed smoking rooms in healthcare facilities, while in Greece there is a partial smoking ban in bars, having smoking areas or some exceptions in enclosed public places and other workplaces. Poland has a total smoking ban only in enclosed public places and in healthcare facilities, while smoking rooms are allowed in restaurants, bars and other workplaces, airports and waiting halls in bus and train stations. In Romania, a total smoke-free ban exists only in healthcare facilities and in public transportation, while smoking may be allowed in restaurants and bars smaller than $100 \mathrm{~m}^{2}$ and enclosed smoking rooms are allowed in larger restaurants and bars, as well as in other workplaces and enclosed public places. Smoke-free legislation in Germany is regulated at the regional level; in most states, separate, enclosed smoking rooms are allowed, while smaller establishments that do not serve food are exempted from the smoking ban altogether. Total smoking bans for restaurants and bars are in place in Saarland, Bavaria and North Rhine-Westphalia ${ }^{12}$.

The objective of this study is to describe the level of support for smoke-free policies among smokers from these six European countries and to examine its relationship with opinions about the harms of secondhand smoke to non-smokers. This work adds new evidence in this regard, with recent and wider information about the support for smoke-free regulations in Europe.

\section{METHODS}

\section{Design}

The EUREST-PLUS ITC 6E Survey includes representative samples of approximately 1000 smokers in Germany, Greece, Hungary, Poland, Romania, and Spain $(n=6011)$. The methods used in the survey are explained elsewhere ${ }^{11,13}$. Briefly, samples of adult current smokers aged 18 years and over (having smoked $>100$ cigarettes in their lifetime and having smoked at least once in the past 30 days) were recruited, being representative of all geographic regions in each of the six EU Member States (MS). Using a randomwalk method, households were randomly selected and were considered to be eligible if they included at least one eligible smoker. Where available, one male and one female smoker were selected from each household using the last birthday method ${ }^{14}$. The current study analysed the data of the inception cohort (Wave 1 data) of the EUREST-PLUS Project that was collected over a month period in each EU MS between June and September 2016. After informed consent was provided, a computer-assisted personal interview (CAPI) was conducted. The study protocol was approved by an ethics committee in each of the participating countries. The participants received a small remuneration for their participation. The sociodemographic characteristics of the sample are provided elsewhere ${ }^{15}$. 


\section{Measures}

Opinions about smoking in different places

These were determined with the question: 'At which of the following places do you think smoking SHOULD be allowed?'. The places included were: on outdoor terraces of bars, pubs and restaurants, within $5 \mathrm{~m}$ of entrances to public buildings, in cars with pre-school children, in cars with non-smokers, in schoolyards of primary and secondary schools, at beaches, in open stadiums, at bus stops, and in subway and train stations. The possible answers were: 'strongly support', 'support', 'oppose' and 'strongly oppose', which were recoded as 'support' (first and second possible answers) and 'oppose' (third and last possible answers).

Support for a complete smoking ban inside public places This was determined with the question: 'Do you support or oppose a complete smoking ban in...?'. The places enquired were: hospitals and healthcare facilities, inside restaurants, drinking establishments such as pubs and bars, and entertainment establishments such as nightclubs and discos. The possible answers were: 'strongly support', 'support', 'oppose' and 'strongly oppose', which were recoded as 'support' (the first two possible answers) and 'oppose' (the last two possible answers).

Belief about the harmfulness of secondhand smoke to non-smokers

This was determined with the question: 'Do you strongly agree, agree, neither agree nor disagree, disagree, or strongly disagree with the following statement: "Cigarette smoke is dangerous to nonsmokers"?'. The answers were categorised as 'agree' (those who answered 'strongly agree' and 'agree'), 'neither agree nor disagree', and 'disagree' (those who answered 'disagree' or 'strongly disagree').

\section{Analysis}

We computed the prevalence and 95\% confidence intervals (CI) of the support for smoking regulations in different public settings (responses 'oppose' to allowing smoking in different places) overall and by the six EU MS. We also described the prevalence (and 95\% CI) of support for a complete smoking ban in healthcare facilities, restaurants, pubs/bars and entertainment settings overall and by country, sociodemographic (sex, age, educational level) and smoking characteristics (nicotine dependence measured with the Heaviness of Smoking Index ${ }^{16}$ and quit attempts in the last 12 months). We similarly described the prevalence of the degree of agreement with the belief about the harms of secondhand smoke to non-smokers. Finally, we analysed the relationship between the respondents' opinions about the places where smoking should not be allowed, as well as their support for complete smoking bans in public places, according to the degree of agreement with the belief about the harms of secondhand smoke to nonsmokers. All the analyses incorporated the weights derived from the complex sampling design. We used Stata v.13 to perform all analyses.

\section{RESULTS}

\section{Opinions about smoking in different settings}

In general, participants supported not allowing smoking indoors to a greater extent than in outdoor premises. More than $90 \%$ of smokers supported not allowing smoking in cars with preschool children and in schoolyards of primary and secondary schools, whereas lower support was found for not allowing smoking on outdoor terraces of bars and pubs $(8.6 \%$; 95\% CI: $7.5 \%-9.8 \%)$ and on outdoor terraces of restaurants (10.1\%; 95\% CI: 8.9\%-11.4\%; Figure 1). While there was low variability by country in the support for not allowing smoking in places where

\section{Figure 1. Support for smoke-free policies in different} settings, 2016

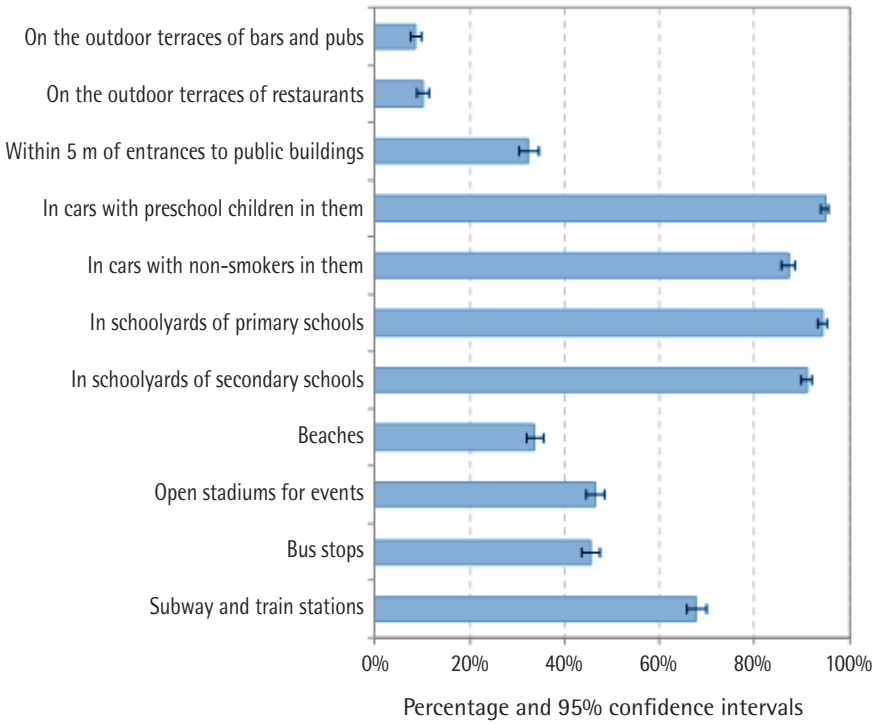


there are minors (support $>85 \%$ in all countries), greater variability was seen for open stadiums, in which the support varied from $24.4 \%$ in Greece to $78.4 \%$ in Poland, and for entrances of public buildings, where the support ranged from $20.5 \%$ in Spain to $69.4 \%$ in Hungary (Table 1).
Support for a complete smoking ban inside public places

Overall, support for complete smoking bans was higher in hospitals and healthcare facilities $(85.3 \%$; 95\% CI: $83.9 \%-86.8 \%)$ and in restaurants $(68.0 \%$; 95\% CI: 66.0-69.9\%; Table 2). Less support was

Table 1. Support for smoke-free policies in different settings by country, 2016

\begin{tabular}{|c|c|c|c|c|c|c|c|c|c|c|c|c|}
\hline & \multicolumn{2}{|c|}{ Germany } & \multicolumn{2}{|c|}{ Greece } & \multicolumn{2}{|c|}{ Itungary } & \multicolumn{2}{|c|}{ Poland } & \multicolumn{2}{|c|}{ Romania } & \multicolumn{2}{|c|}{ Spain } \\
\hline & $\%$ & $95 \% \mathrm{CI}$ & $\%$ & $95^{\circ} \circ \mathrm{CI}$ & $\%$ & $95^{\circ} \mathrm{CI}$ & $\%$ & $95^{\circ} \% \mathrm{CI}$ & $\%$ & $95^{\circ} \% \mathrm{CI}$ & $\%$ & $95^{\circ} \% \mathrm{CI}$ \\
\hline oor terraces of & 3.5 & $(1.6-5.3)$ & 4.1 & $(2.2-6.0)$ & 22.1 & $(16.8-27.3)$ & 15.5 & $(12.1-18.8)$ & 3.5 & $(2.0-5.0)$ & 3.4 & $(2.1-4.7)$ \\
\hline $\begin{array}{l}\text { On the outdoor terraces of } \\
\text { restaurants }\end{array}$ & 8.5 & $(6.2$ & 5.2 & & 3 & )) & 15.3 & & 3.2 & & 1.2 & 2) \\
\hline $\begin{array}{l}\text { Within } 5 \mathrm{~m} \text { of entrances to } \\
\text { public buildings }\end{array}$ & 1.4 & & 6.8 & $(2$ & 69.4 & & 26.2 & & 30.4 & & 20.5 & \\
\hline $\begin{array}{l}\text { In cars w } \\
\text { children }\end{array}$ & .1 & ) & 98.5 & ( & 92.7 & 6) & 90.9 & & 97.3 & & 92.5 & \\
\hline $\begin{array}{l}\text { In cars with non-smokers } \\
\text { in them }\end{array}$ & 88.0 & . & 88.6 & $(\varepsilon$ & 87.3 & & 86.5 & & 95.1 & & 77.5 & \\
\hline $\begin{array}{l}\text { In schoolyards of primary } \\
\text { schools }\end{array}$ & 97.0 & 98.2) & 94.5 & (91. & 93.4 & (90. & 90.2 & 2.9) & 95.3 & 7.7) & 95.6 & 8.1) \\
\hline $\begin{array}{l}\text { In schoolyards of } \\
\text { secondary schools }\end{array}$ & 88.1 & $(85$. & 92.9 & $(89.6$ & 92.7 & $95.2)$ & 85.7 & 89.0) & 95.2 & $-97.6)$ & 91.2 & $(87$ \\
\hline Beaches & 27.4 & $(22.6-32.1)$ & 11.1 & $(8.1-14.1)$ & 50.6 & $(44.0-57.2)$ & 61.0 & $(56.2-65.9)$ & 38.1 & $(33.0-43.1)$ & 15.7 & $(12.3-19.2)$ \\
\hline Open stadiums for events & 32.5 & $(28.2-36.9)$ & 24.4 & $(18.4-30.3)$ & 65.9 & $(60.6-71.2)$ & 78.4 & $(74.6-82.2)$ & 47.0 & $(40.9-53.1)$ & 31.3 & $(27.0-35.6)$ \\
\hline Bus stops & 26.8 & $(22.5-31.2)$ & 25.8 & $(20.4-31.2)$ & 64.9 & (59.0-70.8) & 72.1 & $(67.7-76.6)$ & 50.3 & $(45.4-55.2)$ & 33.0 & $(28.8-37.2)$ \\
\hline Subway and train stations & 53.6 & $(48.9-58.3)$ & 67.5 & $(60.6-74.5)$ & 69.7 & $(63.6-75.8)$ & 79.5 & $(75.9-83.2)$ & 73.1 & $(68.4-77.8)$ & 63.2 & $(57.7-68.8)$ \\
\hline
\end{tabular}

Table 2. Support for a complete smoking ban inside public places by country, sociodemographic and smoking characteristics, 2016

\begin{tabular}{|c|c|c|c|c|c|c|c|c|c|c|c|c|}
\hline & \multicolumn{3}{|c|}{$\begin{array}{l}\text { Ilospitals and } \\
\text { Inealtheare facilities }\end{array}$} & \multicolumn{3}{|c|}{ Restaurants } & \multicolumn{3}{|c|}{$\begin{array}{l}\text { Drinking } \\
\text { establishments } \\
\text { (pubs, bars) }\end{array}$} & \multicolumn{3}{|c|}{$\begin{array}{l}\text { Entertainment } \\
\text { establishments } \\
\text { (nightclub, discos) }\end{array}$} \\
\hline & n & $\%$ & $95^{\circ} \% \mathrm{CI}$ & n & $\%$ & $95^{\circ} \circ \mathrm{CI}$ & n & $\%$ & $95^{\circ} \% \mathrm{CI}$ & n & $\%$ & $95 \%$ CI \\
\hline All & 5081 & 85.3 & 83.9-86.8 & 3995 & 68.0 & $66.0-69.9$ & 3021 & 51.4 & $49.3-53.5$ & 3078 & 53.2 & $51.1-55.4$ \\
\hline \multicolumn{13}{|l|}{ Country } \\
\hline Germany & 787 & 79.1 & $75.3-82.9$ & 683 & 69.4 & $65.0-73.9$ & 317 & 31.7 & $27.4-36.1$ & 350 & 37.3 & $32.1-42.5$ \\
\hline Greece & 908 & 90.7 & 88.2-93.2 & 490 & 49.0 & $43.2-54.9$ & 301 & 30.8 & $26.1-35.5$ & 288 & 29.9 & $25.1-34.8$ \\
\hline Hungary & 807 & 81.4 & 76.7-86.1 & 702 & 72.0 & $67.1-76.9$ & 507 & 51.1 & $44.7-57.5$ & 559 & 57.0 & $50.8-63.2$ \\
\hline Poland & 881 & 91.2 & 89.1-93.4 & 775 & 81.2 & $77.5-84.8$ & 674 & 72.0 & $67.5-76.6$ & 677 & 72.0 & 67.4-76.5 \\
\hline Romania & 799 & 79.5 & $75.2-83.8$ & 601 & 61.1 & $56.7-65.5$ & 545 & 54.5 & $49.8-59.1$ & 548 & 55.5 & $50.6-60.3$ \\
\hline Spain & 899 & 90.0 & $87.1-92.8$ & 744 & 75.3 & 70.7-79.8 & 677 & 68.9 & $64.2-73.6$ & 656 & 67.5 & $63.1-71.9$ \\
\hline \multicolumn{13}{|l|}{ Sex } \\
\hline Men & 2686 & 84.8 & 82.9-86.6 & 2103 & 67.9 & $65.6-70.2$ & 1582 & 50.8 & $48.3-53.2$ & 1597 & 52.3 & $49.7-54.9$ \\
\hline Women & 2395 & 86.1 & $84.4-87.7$ & 1892 & 68.0 & $65.7-70.3$ & 1439 & 52.2 & $49.8-54.7$ & 1481 & 54.5 & $52.0-57.0$ \\
\hline
\end{tabular}


Table 2. Continued

\begin{tabular}{|c|c|c|c|c|c|c|c|c|c|c|c|c|}
\hline & \multicolumn{3}{|c|}{$\begin{array}{l}\text { Uospitals and } \\
\text { Inealtheare facilities }\end{array}$} & \multicolumn{3}{|c|}{ Restaurants } & \multicolumn{3}{|c|}{$\begin{array}{l}\text { Drinking } \\
\text { establishnments } \\
\text { (pulbs, bars) }\end{array}$} & \multicolumn{3}{|c|}{$\begin{array}{l}\text { Entertainment } \\
\text { establishments } \\
\text { (nightclub, discos) }\end{array}$} \\
\hline & n & $\%$ & $95 \% \mathrm{CI}$ & n & $\%$ & $95^{\circ} \circ \mathrm{CI}$ & n & $\%$ & $95 \%$ CI & $n$ & $\%$ & $95^{\circ} \circ \mathrm{CI}$ \\
\hline \multicolumn{13}{|c|}{ Age (years) } \\
\hline $18-24$ & 426 & 83.5 & $79.7-87.4$ & 325 & 61.3 & $56.3-66.3$ & 226 & 43.0 & $37.7-48.2$ & 212 & 40.8 & $35.7-45.8$ \\
\hline $25-39$ & 1502 & 85.5 & $83.3-87.6$ & 1216 & 69.6 & $66.7-72.6$ & 923 & 53.5 & $50.3-56.7$ & 937 & 54.8 & $51.6-58.0$ \\
\hline $40-54$ & 1717 & 86.5 & $84.7-88.4$ & 1330 & 69.1 & $66.7-71.6$ & 966 & 51.2 & $48.4-54.1$ & 1006 & 53.6 & $50.8-56.4$ \\
\hline$\geq 55$ & 1436 & 84.2 & $81.8-86.5$ & 1124 & 66.8 & $63.9-69.8$ & 906 & 52.5 & $49.4-55.5$ & 923 & 56.1 & $52.8-59.3$ \\
\hline \multicolumn{13}{|c|}{ Educational level } \\
\hline Low & 1843 & 83.9 & $81.7-86.2$ & 1469 & 67.8 & $64.9-70.7$ & 1088 & 50.4 & $47.2-53.6$ & 1131 & 53.0 & $49.6-56.3$ \\
\hline Moderate & 2641 & 85.7 & $84.1-87.4$ & 2075 & 68.5 & 66.4-70.6 & 1595 & 53.0 & $50.5-55.5$ & 1604 & 54.2 & $51.5-56.8$ \\
\hline High & 568 & 88.3 & $85.9-90.8$ & 431 & 66.2 & $61.3-71.0$ & 322 & 47.8 & $43.4-52.3$ & 326 & 50.4 & $45.8-55.0$ \\
\hline \multicolumn{13}{|c|}{ Nicotine dependence } \\
\hline Low & 2020 & 86.0 & $84.0-87.9$ & 1723 & 74.6 & $72.2-76.9$ & 1296 & 56.0 & $53.3-58.7$ & 1327 & 58.7 & $55.9-61.4$ \\
\hline Moderate & 2351 & 84.6 & $82.7-86.4$ & 1781 & 64.9 & $62.4-67.3$ & 1364 & 49.8 & $47.1-52.5$ & 1383 & 51.0 & $48.4-53.6$ \\
\hline High & 433 & 83.9 & $80.5-87.4$ & 271 & 53.6 & $48.1-59.1$ & 200 & 39.2 & $33.6-44.7$ & 202 & 40.6 & $35.4-45.8$ \\
\hline \multicolumn{13}{|c|}{$\begin{array}{l}\text { Quit attempts in the last } 12 \\
\text { months }\end{array}$} \\
\hline Yes & 927 & 87.1 & $84.5-89.8$ & 781 & 73.9 & $70.6-77.2$ & 613 & 57.8 & $54.3-61.3$ & 625 & 60.2 & $56.7-63.8$ \\
\hline No & 4150 & 85.0 & $83.5-86.5$ & 3210 & 66.7 & $64.6-68.8$ & 2404 & 50.0 & $47.8-52.3$ & 2449 & 51.8 & $49.5-54.0$ \\
\hline
\end{tabular}

declared for entertainment establishments (53.2\%; 95\% CI: 51.1\%-55.4\%) and drinking establishments (51.4\%; 95\% CI: 49.3\%-53.5\%). Of the six countries, smokers from Poland showed the highest support for a complete smoking ban. Overall, women showed greater support than men, as did respondents over 25 years of age. Respondents who had low nicotine dependence, as well as those who had attempted to quit in the last 12 months also showed greater support for a complete ban. Results by country are provided in the Supplementary Table S1.

\section{Beliefs about the harms of secondhand smoke to non-smokers}

Overall, most smokers agreed that secondhand smoke is dangerous to non-smokers (77.6\%; 95\% CI: $75.8 \%-79.5 \%)$. This agreement was over $80 \%$ in most countries, except in Germany and Hungary (Table $3)$. The highest agreement was observed in Romania (88.3\%; 95\% CI: 85.1\%-91.5\%) and Spain (86.6\%; 95\% CI: 83.6\%-89.6\%), among women (79.6\%; 95\% CI: $77.6 \%-81.7 \%)$, in the $25-54$ age groups $(78.3 \%$; 95\% CI: $75.8 \%-80.8 \%$ ), among respondents with high educational level (80.4\%; 95\% CI: 76.9\%-84.0\%), and among respondents with low nicotine dependence (78.1\%; 95\% CI: 75.7\%-80.5\%). The agreement with the statement about the harms of secondhand smoke to non-smokers was also higher among smokers who tried to quit in the last 12 months in all six countries (85.3\%; 95\% CI: 83.0\%-87.7\%; Table 3), although this difference was statistically significant only in Hungary (77.5\%; 95\% CI: $69.0 \%-86.0 \%$ vs $61.4 \%$; $95 \%$ CI: $55.7 \%-67.1 \%$ of those without any attempt to quit smoking; Supplementary Table S2).

We analysed the relationship between the respondents' opinions about the places where smoking should be banned and the degree to which they believed that secondhand smoke was harmful to non-smokers. We observed that the support for a complete smoking ban was consistently higher among those who agreed with the statement that secondhand smoke is dangerous to non-smokers compared to those who did not agree with the statement; this pattern held true for all settings except for outdoor terraces of bars, pubs and restaurants, where no clear trend was observed (Table 4). The support for a complete smoking ban was lower than $35 \%$ for all outdoor settings, including outdoor terraces of bars and 
Table 3. Belief about the harms of secondhand smoke to non-smokers by country, sociodemographic and smoking characteristics, 2016

\begin{tabular}{|c|c|c|c|c|c|c|c|c|c|}
\hline & \multicolumn{9}{|c|}{ 'Cigarette smoke is dangerous to non smokers' } \\
\hline & \multicolumn{3}{|c|}{ Agree } & \multicolumn{3}{|c|}{$\begin{array}{c}\text { Veither agree nor } \\
\text { disagree }\end{array}$} & \multicolumn{3}{|c|}{ Disagree } \\
\hline & $n$ & $\%$ & $95 \% \mathrm{CI}$ & n & $\%$ & $95^{\circ} \% \mathrm{CI}$ & 11 & $\%$ & $95 \%$ CI \\
\hline All & 4623 & 77.6 & (75.8-79.5) & 1003 & 17.1 & $(15.5-18.6)$ & 341 & 5.3 & $(4.6-6.1)$ \\
\hline \multicolumn{10}{|l|}{ Country } \\
\hline Germany & 663 & 64.7 & (59.3-70.0) & 241 & 26.0 & $(21.2-30.8)$ & 92 & 9.3 & $(6.9-11.8)$ \\
\hline Greece & 816 & 80.3 & (75.8-84.9) & 130 & 15.0 & $(11.3-18.7)$ & 52 & 4.7 & $(3.0-6.3)$ \\
\hline Hungary & 610 & 63.1 & (57.7-68.5) & 305 & 30.1 & $(25.0-35.2)$ & 70 & 6.8 & $(4.7-9.0)$ \\
\hline Poland & 817 & 82.5 & $(78.8-86.1)$ & 134 & 13.5 & $(10.5-16.6)$ & 46 & 4.0 & $(2.5-5.5)$ \\
\hline Romania & 860 & 88.3 & $(85.1-91.5)$ & 94 & 7.9 & $(5.7-10.2)$ & 40 & 3.8 & $(2.2-5.4)$ \\
\hline Spain & 857 & 86.6 & (83.6-89.6) & 99 & 9.9 & $(7.3-12.5)$ & 41 & 3.5 & $(2.4-4.6)$ \\
\hline \multicolumn{10}{|l|}{ Sex } \\
\hline Men & 2397 & 76.1 & $(74.0-78.2)$ & 559 & 18.3 & $(16.5-20.2)$ & 191 & 5.6 & $(4.6-6.5)$ \\
\hline Women & 2226 & 79.6 & $(77.6-81.7)$ & 444 & 15.4 & (13.6-17.0) & 150 & 5.0 & $(4.2-5.9)$ \\
\hline \multicolumn{10}{|c|}{ Age (years) } \\
\hline $18-24$ & 378 & 76.9 & (73.1-80.6) & 78 & 15.0 & $(11.6-18.5)$ & 49 & 8.1 & $(5.7-10.5)$ \\
\hline $25-39$ & 1365 & 78.3 & $(75.8-80.7)$ & 299 & 16.8 & $(14.7-19.0)$ & 100 & 4.9 & $(3.9-5.9)$ \\
\hline $40-54$ & 1555 & 78.3 & (75.8-80.8) & 344 & 16.9 & $(14.7-19.1)$ & 93 & 4.8 & $(3.7-5.9)$ \\
\hline$\geq 55$ & 1325 & 76.1 & $(72.9-79.2)$ & 282 & 18.3 & $(15.4-21.3)$ & 99 & 5.6 & $(4.4-6.7)$ \\
\hline \multicolumn{10}{|c|}{ Educational level } \\
\hline Low & 1639 & 74.6 & $(71.7-77.5)$ & 399 & 19.2 & $(16.5-21.8)$ & 148 & 6.2 & $(5.1-7.3)$ \\
\hline Moderate & 2438 & 79.2 & $(77.1-81.3)$ & 489 & 15.8 & $(14.1-17.6)$ & 164 & 5.0 & $(3.9-6.0)$ \\
\hline High & 517 & 80.4 & $(76.9-84.0)$ & 109 & 15.4 & $(12.3-18.5)$ & 27 & 4.2 & $(2.9-5.5)$ \\
\hline \multicolumn{10}{|c|}{ Nicotine dependence } \\
\hline Low & 1843 & 78.1 & $(75.7-80.5)$ & 385 & 16.9 & $(14.8-19.0)$ & 122 & 5.0 & $(3.9-6.1)$ \\
\hline Moderate & 2145 & 77.1 & $(74.8-79.4)$ & 486 & 17.5 & $(15.4-19.7)$ & 164 & 5.4 & $(4.4-6.3)$ \\
\hline High & 376 & 75.6 & $(71.5-79.6)$ & 93 & 17.7 & $(14.1-21.3)$ & 38 & 6.7 & $(4.7-8.7)$ \\
\hline \multicolumn{10}{|c|}{ Quit attempts in the last 12 months } \\
\hline Yes & 904 & 85.3 & $(83.0-87.7)$ & 112 & 10.1 & $(8.1-12.1)$ & 56 & 4.6 & $(3.4-5.8)$ \\
\hline No & 3714 & 76.0 & $(74.0-78.0)$ & 891 & 18.5 & $(16.8-20.3)$ & 285 & 5.5 & $(4.7-6.3)$ \\
\hline
\end{tabular}

Table 4. Opinion about the danger of secondhand smoke to non-smokers according to the support for a smoking ban in different places, 2016

\begin{tabular}{|c|c|c|c|c|c|c|c|c|c|c|c|c|}
\hline \multirow{3}{*}{$\begin{array}{l}\text { Places where smoking } \\
\text { should be banned }\end{array}$} & \multicolumn{12}{|c|}{ 'Cigarette smoke is dangerous to non smokers' } \\
\hline & \multicolumn{3}{|c|}{ A/I } & \multicolumn{3}{|c|}{ Agree } & \multicolumn{3}{|c|}{$\begin{array}{l}\text { Veither agree nor } \\
\text { disagree }\end{array}$} & \multicolumn{3}{|c|}{ Disagree } \\
\hline & n & $\%$ & $95 \% \mathrm{CI}$ & 11 & $\%$ & $95 \% \mathrm{CI}$ & $n$ & $\%$ & $95^{\circ} \% \mathrm{CI}$ & n & $\%$ & $95 \%$ CI \\
\hline \multicolumn{13}{|l|}{$\begin{array}{l}\text { Opinion about the } \\
\text { places where smoking } \\
\text { should be banned }\end{array}$} \\
\hline $\begin{array}{l}\text { On the outdoor terrace } \\
\text { of bars and pubs }\end{array}$ & 531 & 8.6 & $(7.5-9.8)$ & 391 & 8.0 & $(6.9-9.1)$ & 103 & 10.4 & $(8.0-12.9)$ & 26 & 9.7 & $(5.6-13.8)$ \\
\hline $\begin{array}{l}\text { On the outdoor terrace } \\
\text { of restaurants }\end{array}$ & 617 & 10.1 & $(8.9-11.4)$ & 452 & 9.4 & $(8.1-10.6)$ & 122 & 12.3 & $(9.6-15.1)$ & 29 & 10.0 & $(6.5-13.5)$ \\
\hline
\end{tabular}


Table 4. Continued

\begin{tabular}{|c|c|c|c|c|c|c|c|c|c|c|c|c|}
\hline \multirow{3}{*}{$\begin{array}{l}\text { Places where smoking } \\
\text { should be banned }\end{array}$} & \multicolumn{12}{|c|}{ 'Cigarette smoke is dangerous to non smokers' } \\
\hline & \multicolumn{3}{|c|}{ AII } & \multicolumn{3}{|c|}{ Agree } & \multicolumn{3}{|c|}{$\begin{array}{l}\text { Veither agree nor } \\
\text { disagree }\end{array}$} & \multicolumn{3}{|c|}{ Disagree } \\
\hline & $n$ & $\%$ & $95 \%$ CI & n & $\%$ & $95 \% \mathrm{CI}$ & n & $\%$ & $95^{\circ} \% \mathrm{CI}$ & n & $\%$ & $95^{\circ} \%$ CI \\
\hline $\begin{array}{l}\text { Within } 5 \mathrm{~m} \text { of the entrance } \\
\text { to public buildings }\end{array}$ & 1897 & 32.4 & $(30.3-34.5)$ & 1479 & 32.7 & $(30.3-35.1)$ & 310 & 32.1 & $(28.2-35.9)$ & 92 & 27.9 & $(22.3-33.5)$ \\
\hline $\begin{array}{l}\text { In cars with preschool } \\
\text { children in them }\end{array}$ & 5601 & 94.8 & $(94.0-95.7)$ & 4362 & 95.4 & $(94.5-96.3)$ & 914 & 94.6 & $(92.9-96.2)$ & 287 & 87.2 & (83.1-91.2) \\
\hline $\begin{array}{l}\text { In cars with non-smokers } \\
\text { in them }\end{array}$ & 5094 & 87.2 & (85.8-88.6) & 4035 & 89.0 & (87.5-90.4) & 782 & 82.7 & $(79.8-85.5)$ & 239 & 73.4 & $(67.6-79.2)$ \\
\hline $\begin{array}{l}\text { In schoolyards of primary } \\
\text { schools }\end{array}$ & 5628 & 94.4 & $(93.3-95.4)$ & 4375 & 94.9 & $(93.7-96.0)$ & 914 & 93.4 & $(91.5-95.3)$ & 298 & 89.9 & $(86.0-93.8)$ \\
\hline $\begin{array}{l}\text { In schoolyards of } \\
\text { secondary schools }\end{array}$ & 5436 & 91.0 & (89.8-92.2) & 4249 & 91.9 & (90.6-93.2) & 878 & 89.8 & $(87.5-92.1)$ & 271 & 80.6 & (75.3-85.9) \\
\hline Beaches & 1992 & 33.7 & $(31.9-35.6)$ & 1574 & 34.2 & $(32.2-36.2)$ & 313 & 33.3 & $(29.3-37.2)$ & 86 & 25.5 & $(19.9-31.0)$ \\
\hline $\begin{array}{l}\text { Open stadiums for events } \\
\text { such as football, etc. }\end{array}$ & 2740 & 46.5 & $(44.4-48.5)$ & 2156 & 47.6 & $(45.3-49.8)$ & 434 & 44.1 & $(40.0-48.2)$ & 125 & 35.6 & $(29.9-41.3)$ \\
\hline Bus stops & 2695 & 45.4 & $(43.5-47.4)$ & 2167 & 47.2 & $(45.1-49.3)$ & 388 & 40.4 & $(36.1-44.7)$ & 120 & 35.3 & $(29.0-41.6)$ \\
\hline Subway and train stations & 3990 & 67.8 & $(65.7-70.0)$ & 3193 & 70.1 & $(67.8-72.4)$ & 587 & 60.9 & $(56.4-65.4)$ & 182 & 56.4 & $(49.7-63.1)$ \\
\hline \multicolumn{13}{|l|}{$\begin{array}{l}\text { Opinion about a complete } \\
\text { smoking ban inside: }\end{array}$} \\
\hline Restaurants & 3995 & 68.0 & $(66.0-69.9)$ & 3187 & 70.3 & $(68.3-72.2)$ & 596 & 61.1 & $(56.5-65.8)$ & 191 & 57.3 & $(50.7-63.8)$ \\
\hline $\begin{array}{l}\text { Drinking establishments } \\
\text { as pubs and bars }\end{array}$ & 3021 & 51.4 & $(49.3-53.5)$ & 2480 & 54.7 & $(52.4-56.9)$ & 401 & 40.5 & $(36.0-45.1)$ & 123 & 38.7 & $(32.2-45.3)$ \\
\hline $\begin{array}{l}\text { Entertainment } \\
\text { establishments such as } \\
\text { nightclubs and discos }\end{array}$ & 3078 & 53.2 & $(51.1-55.4)$ & 2508 & 56.1 & $(53.9-58.4)$ & 424 & 44.0 & $(39.3-48.7)$ & 126 & 39.7 & $(32.9-46.5)$ \\
\hline $\begin{array}{l}\text { Hospitals and healthcare } \\
\text { facilities }\end{array}$ & 5081 & 85.3 & $(83.9-86.8)$ & 3984 & 86.9 & $(85.5-88.3)$ & 809 & 81.7 & $(78.1-85.3)$ & 255 & 72.8 & $(67.3-78.4)$ \\
\hline
\end{tabular}

pubs, restaurants, within $5 \mathrm{~m}$ of entrances to public buildings, and at beaches (Table 4 ). In contrast, in all settings involving the presence of minors (in cars with preschool children and in schoolyards of primary and secondary schools), the support for complete smoking bans was higher than $80 \%$, regardless whether the settings were indoors or outdoors (Table 4 ).

\section{DISCUSSION}

This study examined smokers' opinions about smoking bans in a number of outdoor and indoor settings, some of which are not included in national smoke-free legislation and where non-smokers could be potentially exposed to secondhand smoke. Most smokers from Germany, Greece, Hungary, Poland, Romania, and Spain agreed with regulating smoking in enclosed or semi-enclosed settings, in the presence of non-smokers and particularly in the presence of minors. Similarly, smokers in the six EU MS declared high support for smoking bans in hospitals and healthcare settings. This finding is in line with some previous studies ${ }^{17-19}$ and could be potentially explained by the increased perception of harmful effects of passive exposure in these settings, as well as a wider spread of smoke-free regulations in healthcare settings already in place ${ }^{20}$.

We found higher support for banning smoking in restaurants than in drinking or entertainment establishments. Previous studies based on other ITC surveys in Europe have also found this trend; the support for smoking regulations was about 40$80 \%$ in restaurants and about $10-45 \%$ in bars after the implementation of smoke-free regulations in France, Ireland, the United Kingdom, Scotland, Germany and the Netherlands s,6,8, $^{4,}$ In our survey, when asked about open areas in these settings, we 
found less support for banning smoking in outdoor terraces of restaurants, bars and pubs compared to all the other outdoor settings assessed (entrances to public buildings, beaches, bus stops, open stadiums, and schoolyards). In another ITC survey conducted in France, it was observed that the indoor smoking legislation implemented in 2008 moved smokers to outdoor settings; nevertheless, the ban was also associated with increased non-smoking behaviour and higher support for partial (64.6\%) rather than total bans $(10.2 \%)^{21}$. Another different study conducted in Barcelona, Spain, also showed that the smoking legislation indoors moved smokers to outdoor settings (terraces of pubs and bars), with non-smokers reporting exposure to secondhand smoke in most outdoor settings in which smokers reported smoking after a national comprehensive ban; also, there was great support for smoke-free areas outdoors, particularly for areas in which children are present, for grounds of healthcare centres and, to a lesser extent, for outdoor areas of public transportation, sport centres and university campuse ${ }^{22}$.

In our data, higher support for smoking bans in enclosed public places was observed among smokers of older age, lower nicotine dependence, and having previous quit attempts. Some studies have identified the same smoking-related variables, among others, being associated with the compliance with smokefree legislation ${ }^{23,24}$; this suggests that smokers with these characteristics are more likely to support and comply with smoke-free legislation in enclosed public settings. Also, our data indicated an inverse trend in the support for smoking bans in all indoor settings, according to the smokers' belief about the harms of secondhand smoke to non-smokers, with the highest support among those who agreed with this statement. This result is consistent with findings from the ITC Europe Surveys conducted pre- and post-legislation in France, Germany, Ireland, and the Netherlands, showing that smokers more supportive of smoking bans were more aware of the harmful effects of secondhand smoke exposure ${ }^{25}$. It was also found that high support for smoking bans and a strong belief about the harmful effects of smoking to others was negatively associated with smoking in bars after the legislation $^{25}$.

Overall, smokers' support for smoking regulations may reflect the current state of the smoke-free legislation ${ }^{9,20}$. In other words, smokers report higher support for bans in settings that are already totally or partially regulated by local or national laws, or are located close to places where smoking is currently regulated (e.g. schoolyards or cars with children); and vice versa, the less rigorous the smoking regulation (e.g. in terraces of bars and restaurants), the lower the support for smoking bans. This might suggest a trend of the current regulation to shape smokers' beliefs and support for smoking bans, which is an important reflection of a feasible implementation of smokefree legislation in sensitive settings not affected by such regulation. The enforcement of smoke-free regulations in indoor and outdoor settings where minors are present could be regarded as a priority action, not only for protecting the health of children and adolescents from the exposure to secondhand smoke but also because smokers' support and adherence to such measures is more likely. Following the WHO FGTC recommendations, policymakers should promote the adoption and implementation of effective legislative, executive, administrative or other measures, providing protection from exposure to secondhand smoke in diverse public places and, if appropriate, private settings such as cars with minors.

\section{Limitations and strengths}

The main limitation of this study is the use of selfreported information, particularly when addressing smokers, with a potential information bias due to social desirability. Also, the cross-sectional nature of the study precludes any causal relationship among the studied variables. Further longitudinal analyses will, however, allow for the identification of changes and trends over time. On the other hand, the main strength of this study is the use of nationally representative samples of smokers in six EU MS, five of them with novel data regarding smokers' attitudes towards smoke-free regulations using comprehensive and well-established ITG survey methods.

\section{CONCLUSIONS}

Our data suggest that smokers support smoke-free policies mostly in indoor settings as well as in settings where minors are present. There is less support for smoking bans in outdoor settings, particularly in outdoor terraces of leisure facilities. These results are consistent with their beliefs about the harms of 
secondhand smoke to non-smokers. Lower support for smoke-free regulations in outdoor settings indicates that further efforts are required to increase smokers' awareness about the potential exposure to secondhand smoke in specific outdoor areas such as terraces as well as near entrances of public buildings.

**EUREST-PLUS consortium members:

European Network on Smoking and Tobacco Prevention (ENSP), Belgium: Constantine I. Vardavas, Andrea Glahn, Christina N. Kyriakos, Dominick Nguyen, Katerina Nikitara, Cornel Radu-Loghin, Polina Starchenko University of Crete (UoC), Greece: Aristidis Tsatsakis, Charis Girvalaki, Chryssi Igoumenaki, Sophia Papadakis, Aikaterini Papathanasaki,

Manolis Tzatzarakis, Alexander I. Vardavas

Kantar Public (TNS), Belgium: Nicolas Bécuwe, Lavinia Deaconu, Sophie Goudet, Christopher Hanley, Oscar Rivière

Smoking or Health Hungarian Foundation (SHHF), Hungary: Tibor Demjén, Judit Kiss, Piroska A. Kovács

Catalan Institut of Oncology (ICO); Bellvitge Biomedical Research Institute (IDIBELL), Spain: Esteve Fernández, Yolanda Castellano, Marcela Fu, Sarah 0. Nogueira, Olena Tigova

Kings College London (KCL), United Kingdom: Ann McNeill, Katherine East, Sara C. Hitchman

Cancer Prevention Unit and WHO Collaborating Centre for Tobacco Control, German Cancer Research Center (DKFZ), Germany: Ute Mons, Sarah Kahnert

National and Kapodistrian University of Athens (UoA), Greece: Yannis Tountas, Panagiotis Behrakis, Filippos T. Filippidis, Christina Gratziou, Paraskevi Katsaounou, Theodosia Peleki, loanna Petroulia, Chara Tzavara Aer Pur Romania, Romania: Antigona C. Trofor, Marius Eremia, Lucia Lotrean, Florin Mihaltan

European Respiratory Society (ERS), Switzerland; Goethe University Frankfurt, Germany: Gernot Rohde, Tamaki Asano, Claudia Cichon, Amy Far, Céline Genton, Melanie Jessner, Linnea Hedman, Christer Janson, Ann Lindberg, Beth Maguire, Sofia Ravara, Valérie Vaccaro, Brian Ward

Maastricht University, the Netherlands: Marc Willemsen, Hein de Vries, Karin Hummel, Gera E. Nagelhout

Health Promotion Foundation (HPF), Poland: Witold A. Zatoński, Aleksandra Herbeć, Kinga Janik-Koncewicz, Krzysztof Przewoźniak, Mateusz Zatoński University of Waterloo (UW); Ontario Institute for Cancer Research, Canada: Geoffrey T. Fong, Thomas K. Agar, Pete Driezen, Shannon Gravely, Anne C. K. Quah, Mary E. Thompson

\section{REFERENCES}

1. IARC Working Group on the Evaluation of Carcinogenic Risks to Humans. Tobacco smoke and involuntary smoking. Lyon: International Agency for Research on Cancer; 2004.

2. World Health Organization. WHO report on the global tobacco epidemic 2009: implementing smoke-free environments. Geneva: WHO Press; 2009.

3. Eriksen MP, Mackay J, Schluger N, Islami F, Drope J. The Tobacco Atlas, Fifth edition. Atlanta: American Cancer Society; 2015.

4. Fong GT, Craig LV, Guignard R, et al. Evaluation of the smoking ban in public places in France one year and five years after its implementation: Findings from the ITC France survey. Bull Epidemiol Hebd (Paris). 2013;20(21):217-223.

5. Fong GT, Craig LV, Guignard R, et al. Evaluating the Effectiveness of France's Indoor Smoke-Free Law 1
Year and 5 Years after Implementation: Findings from the ITC France Survey. PLoS ONE. 2013;8(6):e66692. doi: 10.1371/journal.pone.0066692

6. Fong GT, Hyland A, Borland R, et al. Reductions in tobacco smoke pollution and increases in support for smoke-free public places following the implementation of comprehensive smoke-free workplace legislation in the Republic of Ireland: findings from the ITC Ireland/ UK Survey. Tob Control. 2006;15(Suppl 3):iii51-iii58. doi:10.1136/tc.2005.013649

7. Brown A, Moodie C, Hastings G. A longitudinal study of policy effect (smoke-free legislation) on smoking norms: ITC Scotland/United Kingdom. Nicotine Tob Res. 2009;11(8):924-932. doi:10.1093/ntr/ntp087

8. Hyland A, Hassan LM, Higbee C, et al. The impact of smokefree legislation in Scotland: results from the Scottish ITC: Scotland/UK longitudinal surveys. Eur J Public Health. 2009;19(2):198-205. doi:10.1093/eurpub/ckn141

9. Mons U, Nagelhout GE, Guignard R, et al. Comprehensive smoke-free policies attract more support from smokers in Europe than partial policies. Eur J Public Health. 2012;22(Suppl 1):10-16. doi:10.1093/eurpub/ckr202

10. Official Journal of the European Union. Directive 2014/40/EU of the European Parliament and of the Council of 3 April 2014 on the approximation of the laws, regulations and administrative provisions of the Member States concerning the manufacture, presentation and sale of tobacco and related products and repealing Directive 2001/37/EC. OJ. 2014;L127(57):1-38. http://data. europa.eu/eli/dir/2014/40/oj. Accessed March, 2018.

11. Vardavas CI, Bécuwe N, Demjén T, et al. Study Protocol of European Regulatory Science on Tobacco (EUREST-PLUS): Policy implementation to reduce lung disease. Tob Induc Dis. 2018;16(Suppl 2:A2). doi:10.18332/tid/93305

12. European Commission. Overview of smoke-free legislation and its implementation in the EU. https:// ec.europa.eu/health/sites/health/files/tobacco/docs/ smoke-free_legislation_overview_en.pdf. Accessed December 1, 2018.

13. Fong GT, Thompson ME, Boudreau C, et al. The Conceptual Model and Methods of Wave 1 (2016) of the EUREST-PLUS ITC 6 European Countries Survey. Tob Induc Dis. 2018;16(Suppl 2:A3). doi:10.18332/tid/99881

14. Binson D, Canchola JA, Catania JA. Random Selection in a National Telephone Survey: A Comparison of the Kish, Next-Birthday, and Last-Birthday Methods. J Off Stat. 2000;16(1):53-59. https://www.scb.se/contentassets/ f6bcee6f397c4fd68db6452fc9643e68/random-selectionin-a-national-telephone-survey-a-comparison-of-thekish-next-birthday-and-last-birthday-methods.pdf. Accessed December 1, 2018.

15. Demjén T, Kiss J, Kovács PA, et al. The purchase sources of and price paid for cigarettes in six European 
countries: Findings from the EUREST-PLUS ITC Europe Surveys. Tob Induc Dis. 2018;16(Suppl 2:A16). doi:10.18332/tid/100413

16. Heatherton TF, Kozlowski LT, Frecker RC, Rickert W, Robinson J. Measuring the heaviness of smoking: using self-reported time to the first cigarette of the day and number of cigarettes smoked per day. Br J Addict. 1989;84(7):791-800. doi:10.1111/j.1360-0443.1989.tb03059.x

17. Thomson G, Wilson N. Public attitudes to laws for smoke-free private vehicles: a brief review. Tob Control. 2009;18(4):256-261. doi:10.1136/tc.2008.027672

18. International Agency for Research on Cancer. Evaluating the effectiveness of smoke-free policies. In: IARC Handbooks of Cancer Prevention, Tobacco Control. Vol. 13. Lyon, France: IARC; 2009.

19. European Comission. Special Eurobarometer 458. Attitudes of Europeans towards tobacco and electronic cigarettes. https://publications.europa.eu/en/ publication-detail/-/publication/2f01a3d1-0af2-11e8966a-01aa75ed71a1/language-en. Published May, 2017. Accessed December 1, 2018.

20. World Health Organization. WHO report on the global tobacco epidemic, 2017: monitoring tobacco use and prevention policies. Geneva: World Health Organization; 2017.

21. Kennedy RD, Behm I, Craig L, et al. Outdoor smoking behaviour and support for outdoor smoking restrictions before and after France's national smoking ban. Eur J Public Health. 2012;22(Suppl 1):29-34. doi:10.1093/eurpub/ckr208

22. Sureda X, Fernández E, Martínez-Sánchez JM, et al. Secondhand smoke in outdoor settings: smokers' consumption, non-smokers' perceptions, and attitudes towards smoke-free legislation in Spain. BMJ Open. 2015;5(4):e007554. doi:10.1136/bmjopen-2014-007554

23. Lazuras L, Eiser JR, Rodafinos A. Predicting smokers' non-compliance with smoking restrictions in public places. Tob Control. 2009;18(2):127-131. doi:10.1136/tc.2008.025841

24. Zhou L, Niu L, Jiang H, Jiang C, Xiao S. Facilitators and Barriers of Smokers' Compliance with Smoking Bans in Public Places: A Systematic Review of Quantitative and Qualitative Literature. Int J Environ Res Public Health. 2016;13(12):1228. doi:10.3390/ijerph13121228

25. Nagelhout GE, Mons U, Allwright S, et al. Prevalence and predictors of smoking in 'smoke-free' bars. Findings from the International Tobacco Control (ITC) Europe Surveys. Soc Sci Med. 2011;72(10):1643-1651. doi:10.1016/j.socscimed.2011.03.018
ACKNOWLEDGEMENTS

We thank the ITC Project Team at the University of Waterloo, and in particular P Driezen, for support in ITC dataset management and preliminary data analysis.

\section{CONFLICTS OF INTEREST}

The authors declare that they have no competing interests, financial or otherwise, related to the current work. K Przewoniak reports grants and personal fees from Polska Liga Walki Z Rakiem (Polish League Against Cancer) outside the submitted work. $\mathrm{Cl}$ Vardavas reports that he is the Strategic Development Editor of TID and that there are no conflicts of interest with this current work. The rest of the authors have also completed and submitted an ICMJE form for disclosure of potential conflicts of interest.

\section{FUNDING}

The EUREST-PLUS project has received funding from the European Union's Horizon 2020 research and innovation programme under grant agreement No 681109 (CIV) and the University of Waterloo (GTF). Additional support was provided to the University of Waterloo by a foundation grant from the Canadian Institutes of Health Research (FDN-148477). GTF was supported by a Senior Investigator Grant from the Ontario Institute for Cancer Research. Authors EF, MF, OT and YC are supported by the Ministry of Universities and Research, Government of Catalonia (2017SGR319). EF was supported by the Instituto de Salud Carlos III, Government of Spain (INT16/00211 and INT17/00103), cofunded by the European Regional Development Fund (FEDER). 